\title{
HIGH LEVELS OF STRESS CAUSING ANXIETY AMONGST MEDICAL STUDENTS
}

\author{
Reshma Fateh, Sateesh Babu Arja, Sireesha Bala Arja, Tarig Fadlallah Altahir \\ Ahmed, Praveen Kottath Veetil, Kumar Ponnusamy *.
}

Avalon University School of Medicine, Willemstad, Curacao, Netherland Antillies.

\section{ABSTRACT}

\begin{abstract}
The medical students undergo tremendous stress and mental pressure during their academic life and clinical studies. The high level of anxiety and depression among medical students is very common occurrence combined with the academic pressure that has a severe impact on their mental and physical health. The current study aims to explore various articles presented by scholars in the field of analysing the impact of stress causing anxiety and depression in medical students and evaluating its impact on prevalence of depression among medical students. This study critically analyses and reviews articles published in this decade for analysing the role of depression and anxiety and experiences of medical students and the reaction to stress. The central idea of the study understands different perspectives presented by scholars in the field of stress and anxiety and its prevalence among the medical students highlighting the causes and key issues. This is vital for understanding the critical factors affecting the mental health and physical well-being of the medical students in order to derive suggestions for early identification and providing for support by the medical schools. The study had used electronic databases for rummaging and reviewing literature articles published on stress and other psychological determinants among medical students and management of stress. In the current study, data were extracted through reviewing various related research articles focusing more on the prevalence and suggest possible stress management strategies in medical students. The current study focuses on findings and views of different scholars with stress as an epicentre of discussion and other factors such as environmental factors, social and economic factors and so on that directly or indirectly impacts on the medical student's mental health. The purpose of the study to analyse the research articles to acknowledge the quantum of research done in the field of understanding the causes and impact of stress and depression among medical students and mark the areas where further research can be conducted.
\end{abstract}

KEY WORDS: Depression, Well-Being, Medical Students, Medical School, Mental Health.

Address for correspondence: Dr Kumar Ponnusamy, Chair \& Professor, Department of Biochemistry \& Medical Genetics, Avalon University School of Medicine, Willemstad, Curacao, Netherland Antilles. E-Mail: kumar.ponnusamy@avalonu.org

\begin{tabular}{|c|c|c|}
\hline \multicolumn{3}{|c|}{ Online Access and Article Informtaion } \\
\hline \multirow{2}{*}{$\begin{array}{c}\text { Quick Response code } \\
\text { DOI: } 10.16965 / \text { ijims.2019.124 }\end{array}$} & \multicolumn{2}{|c|}{$\begin{array}{l}\text { International Journal of Integrative Medical Sciences } \\
\text { ISSN (P): } 2394 \text { - 6318. ISSN (E): } 2394-4137 \\
\text { www.imedsciences.com }\end{array}$} \\
\hline & $\begin{array}{l}\text { Received: 14-11-2019 } \\
\text { Revised: 14-01-2020 }\end{array}$ & $\begin{array}{l}\text { Accepted: 21-01-2020 } \\
\text { Published: 31-01-2020 }\end{array}$ \\
\hline Source of Funding: Self & \multicolumn{2}{|c|}{ Conflicts of interest: None } \\
\hline
\end{tabular}

\section{INTRODUCTION}

This review comments on the prevalence and causes of depression and other symptoms of psychological distress in medical students. Stress was also found to correlate with depression and anxiety, showing the inter-dependence of these symptoms. It then explores some of the key issues that have been shown to contribute to high levels of depression, anxiety, and stress and concludes with recommendations for early identification and support.

\section{MATERIALS AND METHODS}

A systematic review on stress, depression or anxiety in medical students and related determinants were conducted. Studies were identified using PubMed, Embase, Medlnd, and Google Scholar databases. The study had used electronic databases for rummaging and reviewing 
literature articles published on stress and other psychological determinants among medical students and management of stress. In the current study, data were extracted through reviewing various related research articles focussing more on the prevalence and suggest possible stress management strategies in medical students. Articles published between January 1, 2000 and December 1, 2019 were included.

Prevalence and causes of depression and anxiety in medical students: Stress is a disturbed state of an organism due to the numerous demands of life situations that demand more adjustments from individuals. It is a normal physical response to demanding life events which are rather complex. Stress is a state of an individual that caused by his/her perceived threat from their environment disturbs their well being. It has been reported that field of education by itself needs a lot of adjustments thus highly stressful to students [1-3]. Since they face demanding adjustment from their university life the need ability to cope, but student's ability varies to manage with campus life and alter to these new challenges, and some students confront more obstacles than others [4]. Several factors can contribute to severe stress and functional impairment. Thus, medical education is even more stressful as evidenced by the high prevalence of stress among medical students [5]. The sense of powerlessness experienced by medical students that further contributes to overall stress [6]. The three main stressors identified are examinations, more workload and financial burden [7]. Medical school in the USA has recognised undergraduate medical student's that $23 \%$ had clinical depression and $57 \%$ were under psychological stress [8-9]. Previous studies have shown that the medical students of in the USA sufferers from a very rate of depression [10]. In Europe, around $30 \%$ of medical students suffer from depression or anxiety [11], a rate similar to that reported by Brazilian studies, in which 20 to $50 \%$ of medical students were found to present with mood disorders [12-13].

A study conducted in Brazil found a higher prevalence of anxiety symptoms in first-year (30.8\%) medical students compared to sixth-year (9.4\%) medical students [14], while an investigation in Malay-sia showed that anxious symptomatology was much more prevalent than depressive symptoms, and that stress in students newly enrolling in medical school was greater than students at the latter stages of the course [15]. Similarly, Quince et al [16] performed a longitudinal study at a UK medical school and found a prevalence of depression rang-ing from 5.7 to $10.6 \%$ in students on the basic years and 2.7 to $8.2 \%$ in students on the clinical stages of the course. $27.2 \%$ of medical students, as reported by Rotenstein et al [17]. were subjected to depression or depressive symptoms in 47 countries. In the Chinese context, medical students also suffer from severe mental diseases, particularly depression and anxiety, which mainly caused by the huge pressure during school [18], the extremely long length of schooling [19].

According to a previous study, the overall global prevalence of depression or depressive symptoms amongst medical students was $27.2 \%$ [20]. The prevalence of depression and anxiety outside the North American region was 7.7-65.5\% and 6.0-66.5\%, respectively [21]. In Turkey, depression and anxiety prevalence rates of 39.0 and $35.8 \%$ were reported, respectively [22]. In North America, the degrees of depression and anxiety were associated with cigarette addiction, alcoholism, and sleeping deprivation [23].

Anxiety, depression and a general sense of 'burnout' may all result from the increased stress experienced by medical students [24-25]. It has been observed in the literature that curriculum in medical schools that is including examination and academic related factors were the most significant stressors [26]. Academic examinations are shown in the reviews that cause higher stress among medical students [27].

The high levels of stress in medical students are important predictors of anxiety and depression [20]. Stress impairs learning, since this directly interferes in the brain's executive functions and can affect the performance of undergraduate students at specific times or throughout their academic course [28]. Stress was also found to positively correlate with depression and anxiety, showing the inter-dependence of these 
symptoms. It has been documented that, the increased distress and lack of time, coupled with the conflicts of choosing a specialty, explain the predominance of stress in internship candidates, a situ-ation confirmed by other authors [29].

In the current study report, which describes the findings of stress among medical students around the globe. Stress and stress related anxiety, depression and other psychological disturbances among medical students. The review addresses the following aspects: Level of stress and distress observed among medical students in various developed and developing countries and the stress management strategies.

In an article Puthran et al (2016) [30] has discussed the multiple factors that a medical student has to face during their clinic or academic study. Therefore, the main emphasis of this article is given on the depression issue that is prevalent among the medical student. In addition to this, recommendations are also provided in the article that will help in the improvement of medical student situation. The main cause that was stated behind the depression of medical student is time pressure, academic requirement as well as the high workload. World health organisation has stated the health as the state of complete medical, physical, as well as social wellbeing. It has also discussed that it is fruitful for the medical leaners to keep them alert of their own place. It is also true that the majority of medical student face difficulty in order to earn high grades. This sometimes led to human suffering to them. Most of the medical students are seen to be the victims of depression.

It has also discussed regarding student motivation. These are the factors that can influence the student wellbeing and learning. Motivation is an essential aspect that will benefit medical learners to sustain a healthy balance amid their individual wellbeing and study demand. It has also discussed that the higher relevancy of depression and anxiety is founded among the medical students across the world. Several types of research have also been done on medical schools. From this research, it is found that most of the medical schools provide a basic psychological environment. In such environment, they come across the financial hardships, workload, and academic pressure as well as sleep depression. Due to this, some of the medical students get poor academic performance. As a result, some of the medical students drops put and some commit suicide. It is also true that when student starting feeling more stress and depression. In the end, they do not have any option left.

In addition to this, it has also discussed that depression among medical student is a complex issue. Due to this, it has given the emphasis to ensure the motivation among these people. Several skills can be helpful in order to beat the competition. Good sense of awareness is also essential among the medical student so that they can easily cope up with the situation. By adopting the wellness approach, it can bring several changes in the attitude of people. It is important for Medical universities to hold the key to effect change and maybe in the greater position to permit medical students, educators, and clinicians to work collectively to develop a better workplace values.

Saravanan and Wilks (2014) [20] has stated that, the medical school is seen as the stressful situation that puts the negative impact on the student educational performance, psychological wellbeing as well as on the physical health [31]. With the help of sample, author has identified the amount of depression that presents among the medical students. Besides this, it is also discussed the amount of stress that causes anxiety and depression among those students. By properly ensuring the sample from medical schools, it is able to disclose the proper projects regarding the percentage of anxiousness and depression. It has also done effective research on the gender basis depression. From the analysis, it is found that the females are found to be more depressed as compared to the male.

From the evidence, it has also shown the relationship between the medical student development of anxiety and depression. It is true that when students feel more burden from their study. They started taking it as stress. When the level of stress increases to a large extent, they started feeling depressed. Several other things are also attached with the depression such as 
distress, relationship, as well as inability to enjoy the difficulties, normal activities, facing situation as well as lack of concentration. Untreated anxiety, as well as depression, is directly related to the poor performance of student, suicidal behaviour, as well as withdrawal of student from the medical course. Several students from medical student are founded to be getting unemployed. Due to this, they also resign from the medical degrees. When student resign from the degree, they are not easily able to switch to the other course. Due to this, they get free for some time and as a result, they start taking every problem as stress.

Due to this, author has also given the emphasis on the condition of medical field students. It has stated that the medical student is seen to be more laborious by getting the negative and burden environment. When any student takes the new admission in the medical field, they found the stressful environment. Moreover, anxiety and depression tend to affect the productivity of the medical student. By ensuring the proper research on the medical students, it has stated that the high pressure on the medical student is the major cause of depression among medical students. It is rightly said that when students study in a stressful environment, they are not able to perform well. As a result, when they appear in any exam, they get less mark. Due to this, they are not able to cope up with the condition. Not coping up with the situation led them the stress. Due to the increasing competition too, students are running toward more study material in order to get more marks. In this condition, they even forget to enjoy their life. When only one thing remains in the life of student, they are not able to focus on all the remaining good things. Because of this, they started taking everything as the burden and start depressing.

In the article Saravanan \& Wilks (2014) [20] has described the several factors that are associated with the stress level in the medical students. Author has discussed that stress depends on several factors such as community, individual, ideology, and socioeconomic aspects. It tends to decrease the working efficiency among the workers. When student becomes emotionally unstable, it tends to hinder the ability of the person to function and focus effectively on a daily basis. It has defined stress as the emerging mental agitation, tension, as well as irritability among people. When students come across a stressful situation during the course, they started feeling depressed. Due to several situations, they do not fit as per the environment. Due to this, several changes are required in the study of medical student. Most of the male, as well as female students, live in the hostel during their study. In such a situation, when they do not get better colleagues, they are not able to study well. They started feeling things emotionally [32].

Several author has also discussed the several environmental factors that affect the medical students. Among all the factors, primary factor is the weather change. It is true that students have to go outside away from their home in order to get better education. In such a situation, student takes time in order to adjust as per that weather. The adjustment with the new environmental condition is itself a challenge for the medical students. Several times student also feels the homesickness. Due to this also, student started facing stress despite their study burden. They are not able to manage the stress of homesickness as well as burden of studies at the same time. Several authors have neglected these basic factors that are prevalent major among medical studen

In addition to the explanation of the factors accusing stress, it has also explained the negative impact of these factors. The major effect of such factor is anxiety and sleeplessness changes in the living environment. From the article, it is reviewed that the absence of quiet and calm environment as stress is faced by most of the hostellers. Time related barrier is also proved the main cause of the depressing situation among the people. The lack of motivation among the students also leads to the lack of self-discipline. This kind of issue is also recognised as the stress-causing element by the author. In addition to these common issues, vast syllabus, increasing workload in exam timing and fewer markets also creates stress among medical students. In this way, author is able to clearly depict the reasons that are responsible for stress and anxiety among the depressing 
student.

Salam et al (2013) [33] have stated that, stress as an exterior constraint which distresses a person both physically and mentally. As per various studies, it has been identified that medical students suffer from greater stress in comparison with other area students.

According to Kendler et al (2010) [34], stress is a condition of a person that comes from the individual communication with the situation which is observed as risk to welfare. It is also termed as externally which directly upsets the individuals. A person in a stressful state is inclined by his or her mental capacity to undertake continuing tasks. With regards to this, a minor level of stress is beneficial that enables the student to become more dynamic and better performer and on the other hand, high stress level leads to poor academic performance, depression, and even suicide. In addition, the three key stressors that have been recognised include examinations, financial accountabilities and class-work $[35,36]$. Students in medical field open to working overload in such a competitive situation with high burden of assessments and examination leaving individual to various changing in their daily lifestyle like irregular diet, lack of sleep and material abuse due smoking and drinking of alcohol. The four key areas connected to stress for medical students include i.e. prevalence of medical student distress, socio-demographics factors linked to student distress, stressors leading to medical student distress and coping mechanism undertake by students to overcome the stress.

In terms of socio demographic research, the first variable was the gender where it was found that in comparison between males and females, it showed higher stress among females. In addition, the rate of stress prevalence was variable amid medical students in relation with different study years. For instance, there is a lower stress prevalence in both final and first year students in contrast with the student of second, third and fourth year [37]. It was also stated that $5^{\text {th }}$ year student may be possibly built out expertise to accomplish their studies and thus able to manage with stress. The other variable was the different university however, there was no significant difference found out. Some other variables include relationship problem, ethnics, marital status, financial problem and other factors.

In stress development, curriculum had long been identified as a significant factor whereas academic and examination related factor considered as more important stressors. In the same way, student who was going for educational examinations had considerably higher stress. Some of important strategies used by students include self-distraction, denial, venting in emotional, behavioural detachment and self-accusing. Other than this, to cope up with such stress, the key practices adopted by medical students include active coping, changing to religion and positive interpretation [38]. In coping strategies, student use both problem focused and emotion focused combination, however, they dominate. Considering intervention, students under thus group gets them to participate in workshop as the short stress reduction intervention. The substantial decrease of depression and anxiety points recommended that brief intervention was effective in the improvement of psychological goodness of exposed medical students at the time of stressful period.

Hence, medical students put themselves into stress by working hard with learning and adopting various knowledge, skills and attitude. It is also revealed that an important correlation amid emotional disorders and medical student relationship with their teachers, paternities, siblings and their examination too. Various intervention programs are also regularly conducted to push awareness and help students to cope up with stressors mainly those associated to academics. Some of the significant coping strategies include self-distraction, positive reframing and emotional venting [39]. These tactics are important to minimise the stressful conditions. Other than this, complex course structure, examinations and training programs are one of the main reason of distress among students. One can say that medical scholars are the future doctors who also represents mental goodness of the patient. Indirectly, to ensure patient safety, it is necessary to consider mental health of these future doctors i.e. medical students. In addition, proper attention 
is required to be given by curriculum planners for taking important procedures to decrease the stress amid the medical learners.

It is a tough work for instructors to turn the impact of stress as a learning stimulus rather than removing it. When the stress becomes excessive and prolonged, it brings decline of mental and physical health [40]. However, there are some beneficial effects of acute stress. Embracing anticipatory measures, it is very necessary to comply both primary and secondary prevention where primary prevention goal is to improve literacy of mental health and psychological goodness with offering workshops on stress management, time management and relaxation teaching. On the other hand, secondary anticipation aims to target 'at risk' group and needs provision on timely manner so that to avoid more impairment and decline. During medical practices, psychometric evaluation at the time of selection of student can benefit in looking at students having greater psychological health to handle the significant stress.

There is no variation in perspective and time resulting change in lecturer role from being a provider of material to more imaginative facilitator and designer of learning experiences. Student needs more support from the teacher as educational process put an inadvertent adverse effect on the psychological strength of student. The aim of teaching is to facilitate learning and it needs a supportive educational environment and all its functions need to intend relieving examination and academic associated stress. This sort of research can be used for further health education program for the prevention of stress amid medical students.

\section{DISCUSSION}

Stress, depression and anxiety are very common among medical students irrelevant to the semesters and country, lack of time management strategies, which are due to more work load, responsibilities and educational environments. A recent study also recommended the need of counselling services and its accessibility to students to curb the morbidities of stress, depression and anxiety [31]. The factors such as family support, personal traits important aspects influencing vulnerability [41] to stress and depression. Medical students' workload, examinations, presentations and assessment brings the new changes need more adoption. Indeed, it influences their sleep, irregular and diet, many get involved in unhealthy habits such as alcohol and smoking to cope with the pressure which is an element of stress [42-43]. Failing to cope with the stressors paves a way for deterioration in academic and professional performances and psychological distress [44]. Stress which is due to the transition to a new environment is the most common stress among the new students [23]. The management of stress should go with student's level of stress and ability to cope with it.

\section{CONCLUSION}

This systematic review highlight the problem of depression and anxiety due to increased stress amongst medical students and the related determinants. The findings shed light on taking measures to create potential solutions to diminish mental health diseases. It can be safely concluded from the study that stress and depression among medical students are highly prevalent and is a complex issue which needs to be addressed urgently. The medical students surrounded by a number of problems including financial hardship academic pressure workload and sleep depression which takes a toll on their mental and physical health. This study focuses on adoption of wellness approach which may bring about changes in the attitude of people and help in developing a better workplace value in the medical universities for collectively taking actions for wellbeing of the medical students. The study thoroughly examines research papers published by authors and brings forward the fact that increasing competition and mounting academic pressure ultimately leads students to living in stressful environment. The article by Saravanan \& Wilks, (2014) [20], points that environmental factors and homesickness among medical students play an important role in creating stressful and pressurizing situations along with peer pressure for medical students to obtain better results.

The underlying conditions which leads to stress and depression among medical students needs to be addressed in order to take corrective 
measures on time and provide assistance to the medical students in order to help them from this distressing situations. The critical review of the research article by Salam et al. (2013) [33] brings forward the importance of health education programs for medical schools that will help in the prevention of stress and depression by taking collective and collaborative steps. In addition, ascertaining the times during which students are most susceptible to psychiatric disturbances may help in the implementation of strategies to promote physical, mental, emotional, and spiritual well-being. These strat-egies might include both individuals and the group as a whole [45], promoting the resumption of healthy habits, and attention to health, leisure, and religiosity [46].

Thus, the current study has been analysed stress among medical students inherits regardless in developed and underdeveloped countries. This study has shown need to make the provisions to have a conducive-learning environment to help the medical students. In consequence, the prerequisite needs for stress management and health education programs for medical students.

\section{REFERENCES}

[1]. Chawla K, Sachdeva V. Domains of stress and coping strategies used by 1 st year medical students. Natl J Physiol Pharm Pharmacol. 2018;8(3):366-369.

[2]. Ruzhenkova VV, Ruzhenkova VA, Lukyantseva, IS, Anisimova NA. Academic stress and its effect on medical students' mental health status. Drug Invention Today. 2018; 10(7):1171-1174.

[3]. Habeeb KA. Prevalence of stressors among female medical students Taibah university. J Taibah Univ Med Sci 2010;5:110 119.

[4]. Tinto V. Leaving College: Rethinking the Causes and Cures of Student Attrition. 2nd ed. Chicago, IL: University of Chicago Press; 1993.

[5]. Jeong Y, Kim JY, Ryu JS, Lee KE, Ha EH, Park H, et al. The associations between social support, health related behaviors, socioeconomic status and depression in medical students. Epidemioln Health 2010;32:e2010009, 1-8.

[6]. Levin R. Beyond "the men of steel". The origins and significance of house staff training stress. Gen Hosp Psychiatry 1988;10:114 121.

[7]. Wolf TM, Faucett JM, Randall HM, Balson PM. Graduating medical students' ratings of stresses, pleasures, and coping strategies. J Med Educ 1988;63:636 642.

[8]. Sherina MS, Rampal L, Kaneson N. Psychological stress among undergraduate medical students. Med J Malaysia 2004;59:207 211.
[9]. Dyrbye LN, Thomas MR, Shanafelt TD. Medical student distress: Causes, consequences, and proposed solutions. Mayo Clin Proc 2005;80:1613 1622.

[10]. Stecker T. Well being in an academic environment. Med Educ 2004;38:465 478.

[11]. Kulsoom B, Afsar NA. Stress, anxiety, and depression among medical students in a multiethnic setting. Neuropsychiatr Dis Treat 2015;11:1713 1722.

[12]. Kumar S. Burnout and doctors: Prevalence, prevention and intervention. Healthcare (Basel) 2016;4: pii: E37, 1-9.

[13]. Abdel Rahman AG, Al Hashim BN, Al Hiji NK, Al Abbad Z. Stress among medical Saudi students at College of Medicine, King Faisal University. J Prev Med Hyg 2013;54:195 199.

[14]. Yusoff MS, Abdul Rahim AF, Yaacob MJ. Prevalence and sources of stress among Universiti Sains Malaysia medical students. Malays J Med Sci 2010;17:30 37.

[15]. Rahman NI, Ismail S, Seman TN, Rosli NF, Jusoh SA, Dali WP, et al. Stress among preclinical medical students of Universiti Sultan Zainal Abidin. J App Pharm Sci 2013;3:76 81.

[16]. Borjalilu S, Mohammadi A, Mojtahedzadeh R. Sources and severity of perceived stress among Iranian medical students. Iran Red Crescent Med J 2015;17:e17767, 1-6.

[17]. O’Reilly E, McNeill KG, Mavor KI, Anderson K. Looking beyond personal stressors: An examination of how academic stressors contribute to depression in Australian graduate medical students. Teach Learn Med 2014;26:56 63.

[18]. Shah M, Hasan S, Malik S, Sreeramareddy CT. Perceived stress, sources and severity of stress among medical undergraduates in a Pakistani medical school. BMC Med Educ 2010;10:2, 1-8.

[19]. Firth J. Levels and sources of stress in medical students. BMJ. 1986; 292(6529):1177-1180.

[20]. Saravanan C, Wilks R. Medical students' experience of and reaction to stress: the role of depression and anxiety. Scientific World Journal. 2014; 2014:737382, 1-8.

[21]. Hope V, Henderson M. Medical student depression, anxiety and distress outside North America: a systematic review. Med Educ. 2014;48:963-979.

[22]. He L-M, Wang Y-Y, Chen Y, Mu C-X, Wang X-W. Cross sectional study on mental health of 1655 minority medical students. Soft Sci Health. 2009;23: 294227.

[23]. Dyrbye LN, Thomas MR, Shanafelt TD. Systematic review of depression, anxiety, and other indicators of psychological distress among U.S. and Canadian medical students. Acad Med. 2006;81:354-373.

[24]. Kulsoom B, Afsar NA. Stress, anxiety, and depression among medical students in a multiethnic setting. Neuropsychiatr Dis Treat 2015;11:1713 1722.

[25]. Kumar S. Burnout and doctors: Prevalence, prevention and intervention. Healthcare (Basel) 2016;4: pii: E37, 1-9. 
[26]. Borjalilu S, Mohammadi A, Mojtahedzadeh R. Sources and severity of perceived stress among Iranian medical students. Iran Red Crescent Med J 2015;17:e17767, 1-5.

[27]. O’Reilly E, McNeill KG, Mavor KI, Anderson K. Looking beyond personal stressors: An examination of how academic stressors contribute to depression in Australian graduate medical students. Teach Learn Med 2014;26:56 63.

[28]. Saravanan C, Wilks R. Medical student's experience of and reaction to stress: the role of depression and anxiety. Scientific World Journal. 2014; 2014:737382, 1-8.

[29]. Millan LR, Rossi E, De Marco OLN. O suicídio entre estudantes de medicina. Rev Hosp Clin Fac Med Univ São Paulo. 1990; 45(3):145-149.

[30]. Puthran R, Zhang, MW, Tam WW, Ho RC. Prevalence of depression amongst medical students: a meta analysis. Med Educ. 2016; 50(4):456-468.

[31]. Iqbal S, Gupta S, Venkatarao E. Stress, anxiety and depression among medical undergraduate students \& their socio-demographic correlates. Indian JMed Res. 2015; 141(3):354-357.

[32]. Wolf MR, Rosenstock JB. Inadequate sleep and exercise associated with burnout and depression among medical students. Acad Psychiatry. 2017;41(2):174 179.

[33]. Salam A, Yousuf R, Bakar SMA, Haque M. Stress among medical students in Malaysia: A systematic review of literatures. Int Med J. 2013; 20(6): 6496-6455.

[34]. Kendler KS, Kessler, RC, Walters EE, MacLean C, Neale MC, Heath, AC, Eaves, LJ. Stressful life events, genetic liability, and onset of an episode of major depression in women. Focus. 2010;8(3):459-470.

[35]. Matthiesen SB, Einarsen S. Perpetrators and targets of bullying at work: Role stress and individual differences. Perspectives on Bullying: Research on Childhood, Workplace, and Cyberbullying, 2015; 22(6):135-146.

[36]. Grayson JL, Alvarez HK. School climate factors relating to teacher burnout: A mediator model. Teaching and teacher education. 2008;24(5):13491363.
[37]. Chang E, Eddins-Folensbee F, Coverdale J. Survey of the prevalence of burnout, stress, depression, and the use of supports by medical students at one school. Acad Psychiatry. 2012;36(3):177-182.

[38]. Hojat M, Vergare MJ, Maxwell K, Brainard G, Herrine SK, Isenberg, GA, Gonnella JS. The devil is in the third year: a longitudinal study of erosion of empathy in medical school. Acad Med. 2009; 84(9):11821191.

[39]. Warnecke E, Quinn S, Ogden K, Towle N, Nelson MR. A randomised controlled trial of the effects of mindfulness practice on medical student stress levels. Med Educ. 2011;45(4):381-388.

[40]. Hassed C, De Lisle, S, Sullivan G, Pier C. Enhancing the health of medical students: outcomes of an integrated mindfulness and lifestyle program. Adv Health Sci Educ Theory Pract. 2009;14(3):387-398.

[41]. Baldassin S, Alves TC, de Andrade AG, Nogueira Martins LA. The characteristics of depressive symptoms in medical students during medical education and training: A cross-sectional study. BMC Med Educ 2008;8(60):1-8.

[42]. Tamaki T, Kaneita Y, Ohida T, Yokoyama E, Osaki Y, Kanda $\mathrm{H}$, et al. Prevalence of and factors associated with smoking among Japanese medical students. J Epidemiol 2010;20:339-345.

[43]. Deasy C, Coughlan B, Pironom J, Jourdan D, Mannix McNamara P. Psychological distress and coping amongst higher education students: A mixed method enquiry. PLoS One 2014;9:e115193:1-23.

[44]. Paro HB, Morales NM, Silva $\mathrm{CH}$, Rezende $\mathrm{CH}$, Pinto RM, Morales RR, et al. Health related quality of life of medical students. Med Educ 2010;44:227 235.

[45]. Tempski P, Bellodi PL, Paro HB, Enns SC, Martins MA, Schraiber LB. What do medical students think about their quality of life? A qualitative study. BMC Med Educ. 2012; 12(106):1-8.

[46]. Zonta R, Robles ACC, Grosseman S. Estratégias de enfrentamento do estresse desenvolvidas por estudantes de medicina da Universidade Federal de Santa Catarina. Rev Bras Educ Med. 2006; 30(3):147-153.

How to cite this article: Reshma Fateh, Sateesh Babu Arja, Sireesha Bala Arja, Tarig Fadlallah Altahir Ahmed, Praveen Kottath Veetil, Kumar Ponnusamy. HIGH LEVELS OF STRESS CAUSING ANXIETY AMONGST MEDICAL STUDENTS. Int J Intg Med Sci 2020;7(1):867-874. DOI: 10.16965/ ijims.2019.124 